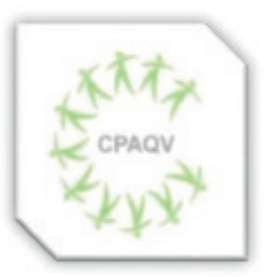

ISSN: 2178-7514
ARTIGO ORIGINAL

\section{FISIOTERAPIA NA REABILITAÇÃO PÓS-CIRÚRGICA DO \\ LIGAMENTO CRUZADO ANTERIOR (LCA)}

\section{Physiotherapy in post-surgical anterior cruciate ligament (ACL) rehabilitation}

Angélica Ariellen Alves; Angelo Antônio Alves Junior

Jussie Fernanda Marques; Selma Fernandes; Thiago Gomes Figueira

Vol. 13 | No. 3| Ano 2021

\title{
RESUMO
}

O joelho é uma das articulações mais importantes e funcionais do nosso corpo. Sendo assim, a probabilidade de lesões nesta área é comumente e extremamente alta. Uma das lesões mais comuns nessa área é a ruptura do ligamento cruzado anterior que se localiza no ventre da articulação. O objetivo deste trabalho foi mostrar a importância do tratamento fisioterapêutico no processo pós-cirúrgico do ligamento cruzado anterior e demonstrar os resultados satisfatórios do processo no qual o paciente foi submetido. Os dados coletados são resultados por meio de materiais e métodos utilizados no tratamento fisioterapêutico do paciente, além de análise do caso e pesquisas de campo sobre o tema trabalhado.

Palavras-chave: Reabilitação do ligamento cruzado anterior, protocolo de reabilitação do LCA, fisioterapia póscirúrgica.

\begin{abstract}
The knee is one of the most important and functional joints in our body. Therefore, the probability of injury in this area is commonly and extremely high. One of the most common injuries is the rupture of the anterior cruciate ligament that is located in the middle of the joint. The purpose of this study was to show the importance of physiotherapeutic treatment in the post-surgical process of the anterior cruciate ligament and demonstrate the satisfactory results of the process in which the patient was submitted. The data collected are results from materials and methods used in the physiotherapeutic treatment of the patient, in addition to case analysis and field research about the theme aimed.
\end{abstract}

Keywords: Rehabilitation of the anterior cruciate ligament, ACL rehabilitation protocol, post-surgical physiotherapy.

Autor de correspondência

Angélica Ariellen Alves - angelariellen309@gmail.com

DOI: $\underline{10.36692 / v 13 n 3-18}$ 


\section{INTRODUÇÃO}

O joelho, sem dúvidas, é uma das articulações mais importantes e funcionais do nosso corpo e, sendo assim, a probabilidade de lesões nesta área é comumente e extremamente alta. Formado por um conjunto de três ossos; fêmur, tíbia, patela e pelas junções femorotibial e femoropatelar, com os ligamentos cruzados anterior e posterior, colateral lateral e colateral medial, menisco medial e menisco lateral que dão todo o suporte necessário para o funcionamento desta articulação do joelho em mobilidades de flexão, extensão, rotação interna e rotação externa ${ }^{(1)}$.

Um exemplo de lesão comum na articulação do joelho é a ruptura do ligamento cruzado anterior (LCA). Este tipo de lesão acontece em quaisquer tipos de situação tais como acidente doméstico, acidente de trabalho, esportes, obesidade, entre outros, sendo que no esporte a prevalência é maior. A forma pela qual é mais acometida é a freada brusca que o atleta se encontra numa determinada velocidade e interrompe o movimento, desacelerando com o pé fixo no chão e com uma leve rotação da tíbia para medial, acontecendo do ligamento entrar num estado de sobrecarga muito alta e não suportar o impacto gerado, podendo romper totalmente ou parcialmente. Estatisticamente falando sobre procedimentos cirúrgicos feitos para as lesões do LCA, que afeta em qualquer pessoa a partir de uma determinada faixa etária, a maior incidência prevalece em jovens atletas. Só nos Estados Unidos, é registrado aproximadamente 200.000 casos anuais e o tratamento cirúrgico se tornou padrão referindo-se aos casos atléticos ${ }^{(2)}$.

Ainda em suas pesquisas, Arliani et al. ${ }^{(2)}$, conclui que o ligamento cruzado anterior (LCA) possui uma importante função de sustentação e estabilização dos movimentos inferiores do corpo humano, a principal finalidade dele é impedir o deslizamento anterior da tíbia em relação ao fêmur e rotação interna, mantendo assim um movimento uniforme. Com o ligamento rompido e não tratado corretamente, não há segurança na marcha, podendo acarretar outros tipos de moléstias como a sobrecarga no joelho oposto ou até bursites.

Os tratamentos para este tipo de comprometimento da lesão podem ser realizados através da cirurgia que consiste em substituir o ligamento lesionado. Atualmente o método mais utilizado é o enxerto, que poderá ser a retirada de um seguimento do tendão patelar ou dos tendões flexores do joelho. Há tentativas com enxerto de ligamentos dos cadáveres em alguns países, portanto esse método é bem pouco utilizado devido à qualidade ser inferior em comparação com um enxerto do próprio paciente. $\mathrm{O}$ enxerto com ligamento sintético já foi experimentado, mas não obteve resultados satisfatórios ${ }^{(3)}$.

Outra opção de tratamento para lesão do LCA é a forma conservadora, na qual se refere ao indivíduo que não se submeteu a cirurgia e obteve uma ruptura total ou parcial do ligamento. O 
tratamento fisioterapêutico em si é bem simples e consiste em analgesia, proteção das estruturas lesionadas, ganho completo de ADM (amplitude de movimento), retorno da função proprioceptiva, trabalhar no retorno das AVDs (atividades de vida diária) e principalmente em fortalecimento dos principais grupos musculares da região que ajudam a sustentar o joelho (quadríceps formado por reto femoral, vasto lateral, vasto medial e vasto intermédio; e isquiotibiais formado por semitendíneo, semimembranoso e bíceps femoral) e posteriormente o retorno às práticas esportivas $^{(4)}$.

De acordo com Vieira et al. ${ }^{(5)}$, alguns pacientes que foram submetidos a cirurgia de reconstrução do ligamento, obtiveram perdas significativas da força muscular do quadríceps, mesmo depois da realização do protocolo de reabilitação pós-cirúrgica. Também podem apresentar quadros de infecção, frouxidão ligamentar, ruptura do tendão patelar após a cirurgia e, como na maioria dos casos que são retiradas partes do próprio tendão ou ligamento do paciente, pode ocorrer certa limitação na amplitude de movimento do grupo muscular de acordo de onde foi retirado.

Este trabalho teve como objetivo mostrar a importância do tratamento fisioterapêutico na pós-cirurgia do ligamento cruzado anterior, localizado no ventre articular do joelho: acompanhando a evolução da reabilitação de um estudo de caso.

\section{MATERIAIS E MÉTODOS}

Trata-se de um relato de caso de um indivíduo submetido a uma cirurgia para substituição do ligamento cruzado anterior. Para a cirurgia foi utilizado obtenção do enxerto dos tendões do semitendíneo e grácil, localizados na parte posterior da coxa. Operado no Hospital HB Saúde (HBS) de Mirassol SP, realizada no dia 24 de Maio de 2021, causada por ruptura total do mesmo. Foi realizado por meio de coleta de dados e pesquisa de campo, analisando de perto o progresso do tratamento específico para reabilitação pós-cirúrgica do joelho.

Paciente M. S. R do sexo masculino, 29 anos de idade, altura de 1,85 m, pesando $85 \mathrm{Kg}$, praticante de esporte físico não profissional, relatou que durante um jogo de vôlei, no momento do salto de bloqueio, um dos jogadores do time adversário pisou em seu pé e acabou batendo contra seu joelho esquerdo. No instante do trauma sentiu um estalo e forte dor aguda, finalizando com a queda no chão. Não houve fratura e edema instantâneo no local da lesão.

Através de exames realizados foi diagnosticado com ruptura total de LCA e submetido à cirurgia de ligamentoplastia aproximadamente 2 anos e meio após a lesão. No período entre a lesão até a cirurgia, assim que obteve uma significante melhora no quadro de dor no local da lesão, o paciente voltou à rotina normal de sua vida como praticar esporte 
com o auxílio de tensores no joelho esquerdo. Aproximadamente um ano após o acontecido, o paciente sofreu mais uma queda durante a prática esportiva, lesionando novamente a articulação do joelho.

\section{RESULTADO E DISCUSSÃO}

Foi relatada uma diminuição da perimetria na região de quadríceps eisquiotibiais, como mostrado na tabela 1 (a perimetria é feita com uma fita métrica, medindo a circunferência de um determinado membro), leve fraqueza muscular na panturrilha esquerda, limitação de amplitude de movimento em extensão e flexão do joelho esquerdo e fraqueza muscular relevante nos grupos musculares quadríceps e isquiotibiais.

O paciente iniciou o tratamento fisioterapêutico três semanas após o processo cirúrgico, apresentando discreto edema e desconforto na articulação. Nas duas primeiras sessões foram realizadas manobras para estimular a absorção de edema por meio de ultrassom e gelo, não foi realizado o uso de laser em nenhum momento do tratamento por apresentar cicatrização perfeita da cirurgia.

Nas sessões de fisioterapia foram realizados exercícios como: isometria de membros inferiores com o uso de tornozeleira; flexão e extensão do joelho contra a gravidade em decúbito ventral; abdução de quadril com faixa elástica; adução de quadril com arco flexível; fortalecimento de quadríceps e isquiotibiais em flexão e extensão de joelho com tornozeleira em cadeia cinética aberta, pois não foi recomendada pelo médico a descarga total do peso nas primeiras semanas; mobilização patelar; esteira; bicicleta ergométrica após a segunda semana; uso de eletroterapia como: corrente Aussie e ultrassom para a recuperação da função muscular e alívio da dor. O foco principal nas primeiras sessões do tratamento foi o ganho de extensão total do joelho para evoluir na prática de exercícios com peso para o fortalecimento do quadríceps e prevenir o encurtamento dos isquiotibiais, sempre monitorando os graus de segurança da articulação para não correr o risco de um possível estiramento do novo ligamento, já que o paciente iniciou a fisioterapia com 90 graus de flexão e com descarga parcial do peso corporal.

Logo na segunda semana de atendimento, o paciente apresentou uma grande melhora na marcha com descarga total do peso e na força muscular, grau 4 para extensão, grau 5 para flexão e amplitude de movimento quase completa, chegando aos $178^{\circ} \mathrm{em}$ extensão e $125^{\circ}$ em flexão. A utilização da eletroterapia com a corrente Aussie tem mostrado uma melhora significante na recuperação da força muscular na $13^{a}$ semana como demonstrado na tabela 1. 


\begin{tabular}{c|c|c}
\multirow{2}{*}{ Exercícios Fisioterapêuticos } & \multicolumn{2}{c}{$\begin{array}{c}\text { Ciclo do Tratamento } \\
\text { Fisioterapêutico }\end{array}$} \\
\cline { 2 - 3 } & $1^{\text {a Semana }}$ & $13^{\text {a Semana }}$ \\
\hline Força muscular quadríceps & Grau 1 & Grau 4 \\
\hline Força muscular isquiotibiais & Grau 1 & Grau 5 \\
\hline Amplitude de movimento flexão do joelho & $110^{\circ}$ & $130^{\circ}$ \\
\hline Amplitude de movimento extensão do joelho & $170^{\circ}$ & $180^{\circ}$ \\
\hline Perimetria & $62-52-42 \mathrm{~cm}$ & $65-54-44 \mathrm{~cm}$ \\
\hline
\end{tabular}

O paciente em questão foi liberado para prática de atividades físicas moderadas como: academia, caminhada, andar de bicicleta após três meses de tratamento. Deu início à hidroterapia para treinamento de saltos sem impacto; controle da propriocepção do joelho dentro e fora d'água com esfera; iniciando aos poucos agachamentos dentro d'água e prática do esporte apenas com exercícios de fundamentos no vôlei sem salto, com impacto nenhum e evitando movimentos bruscos após cinco meses desde o início do tratamento, mas ainda continua com os atendimentos.
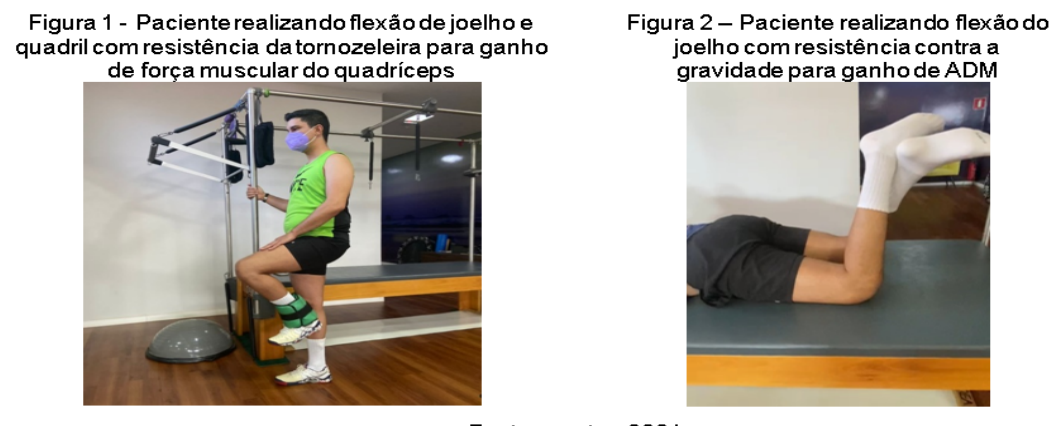

Fonte: o autor, 2021

Acredita-se que pelo fato do indivíduo ser praticante de esportes físicos desde a infância, sua capacidade da restauração muscular seja muito mais rápida e eficaz em comparação com uma pessoa sedentária.

Nos estudos de Seaborne, et al. ${ }^{(6)}$, para a análise da memória muscular epigenética em um indivíduo com atrofia muscular, foi feita a realização de 3 etapas ordenadas que são: carga, interrupção e recarga. Cada etapa durou
7 semanas, totalizando 21 semanas. Nas etapas de carga e recarga são realizados os exercícios de resistência para provocar ganho de massa muscular nos membros inferiores; já a etapa de interrupção foi dada ao descanso das atividades com o intuito de retornar a massa muscular ao nível basal. Na etapa de carga, o exercício é contínuo até a conclusão de 7 semanas e, em seguida, inicia a etapa de interrupção por 7 semanas. Após o descanso, na etapa de recarga, os exercícios são os 
mesmos da etapa inicial. Medindo a cada semana das etapas de carga e recarga, foi confirmado que, após o período de testes, na etapa de recarga, o ganho de massa muscular foi atingido o mesmo da etapa inicial, mas com o tempo menor que sete semanas, mesmo completando todas as semanas de recarga, porém a única forma de análise dos resultados não foi medida a circunferência muscular para comprovar o ganho da massa, mas sim por metilação do DNA do paciente.

A maioria dos pacientes, que foram submetidos ao processo cirúrgico em uma determinada articulação, teve que passar pelo processo de reeducação da propriocepção articular. Com a articulação do joelho não é diferente, inclusive é um dos processos mais importantes no protocolo de reabilitação pós-cirúrgica do ligamento cruzado anterior, contribuindo também na ajuda do paciente lidar com os medos nas etapas do tratamento como: receio do novo ligamento romper novamente ou promover a desestabilização da articulação.

Em uma de suas pesquisas, Paiva et al. ${ }^{(7)}$ também afirma que a reeducação proprioceptiva tem como objetivo desenvolver as habilidades, confiança e eficiência em pacientes que sofreram lesões de LCA, por aumento da velocidade de respostas da defesa e da estabilidade da articulação. Em casos de lesões de LCA, o fortalecimento dos isquiostibiais é essencial, sem esquecer-se do fortalecimento do quadríceps, adutores e abdutores. Este tipo específico de treinamento visa recuperar a autonomia ao paciente, postura em relação aos movimentos e equilíbrio, consciência da posição do peso e da resistência de objetos em relação o corpo.

Segundo Sampaio ${ }^{(8)}$, a fisioterapia busca sempre desenvolver métodos eficientes para que o paciente tenha o retorno satisfatório dos atendimentos o mais rápido possível. Com isso realizou pesquisas e buscas por efeitos instantâneos de um protocolo de eletroterapia em pacientes pós-cirúrgico de LCA. Paciente posicionado em decúbito dorsal, com o pé apoiado em uma bola para estimular ainda mais a extensão do joelho. Foram posicionados os eletrodos na região do quadríceps e ligados à corrente Aussie com frequência $2 \mathrm{KHz}$ com intervalo de $1 \mathrm{~ms}$ de modulação contínua $3 \mathrm{~Hz}$ por aproximadamente 20 minutos. Após o teste do protocolo, foi certificado um ganho total de $14^{\circ}$ de ADM, alcançando a amplitude total em extensão do joelho com apenas uma aplicação.

\section{CONCLUSÃO}

De acordo com a pesquisa relacionada, pode se concluir que a intervenção fisioterapêutica é um fator muito importante na reabilitação póscirúrgica do joelho, pois quanto mais rápido der início ao tratamento, melhor será o prognóstico e progresso do paciente. 


\section{REFERÊNCIAS}

1.SILVA JÚNIOR, N. B.; PACHECO, D. F. Repositório Institucional do Centro Universitário do Planalto Central Apparecido dos Santos, Uniceplac, 2020.

2.ARLIANI, G. G. et al. Lesão do ligamento cruzado anterior: tratamento e reabilitação. Perspectivas e tendências atuais. Scielo Brasil, 2012.

3.GUGLIELMETTI, L. B.; Ligamento Cruzado Anterior (LCA). Dr. Luiz Gabriel, 2018. Disponível em: https://www.drluizgabriel.com.br/ligamento-cruzadoanterior-lca/ Acesso em: 11 jun. 2021.

4.PAPLER, P. G. Reabilitação do joelho. Instituto de Ortopedia e Traumatologia, HC-FMUSP, 1995.

5.VIEIRA, J. B. et al. Avaliação das complicações cirúrgicas de pacientes submetidos à cirurgia de reconstrução de ligamento cruzado anterior. Research, Society and Development, 2021.

6.SEABORNE, R. A. et al. Human Skeletal Muscle Possesses an Epigenetic Memory of Hypertrophy. Scientific Reports, 2018.

7.PAIVA, E. S. et al. Exercícios Físicos como Auxiliares na Prevenção e Reabilitação do joelho: Bases Teóricas. São José dos Campos: XI Encontro Latino Americano de Iniciação Científica e VII Encontro Latino Americano de Pós-Graduação, 2007.

8.CONGRESSO INTERNACIONAL DO CONHECIMENTO CIENTÍFICO, 5, 2015, Rio de Janeiro. Efeito da eletroestimulação no ganho de arco de movimento do joelho em pacientes pós reconstrução do LCA. Rio de Janeiro: biol. \& saúde, 2015. 55 p.

OBSERVAÇÃO: Os autores declaram não existir conflitos de interesse de qualquer natureza. 